\title{
O campo jurídico em Pierre Bourdieu: a produção de uma verdade a partir da noção de propriedade privada nos manuais de Direito
}

\author{
Joaquim Shiraishi Neto*
}

\begin{abstract}
Sumário: Introdução: problema e objetivo; 1. A constituição do campo jurídico; 2. Os manuais como um tipo de conhecimento do Direito; 3. O discurso da propriedade: posições no campo jurídico; Considerações finais. Referências.
\end{abstract}

\begin{abstract}
Resumo: As análises em torno do Direito vêm focalizando prevalentemente ora os elementos formais, ora os instrumentais e, nesse sentido, reduzem a possibilidade de compreensão do próprio Direito. A noção de campo jurídico utilizada por Pierre Bourdieu torna-se um importante instrumento para compreender esse universo social do mundo jurídico, que organiza as relações e delimita os espaços, onde os "operadores do direito" concorrem entre si pelo monopólio do direito de dizer o Direito. Neste sentido, a noção de propriedade privada contida nos manuais de "Direitos Reais" ou de "Direitos das Coisas" permite explicitar esse processo de lutas que ocorre no interior do campo jurídico, evidenciando a construção de uma prática e de um discurso jurídico próprios, cujos objetivos são a produção, reprodução e difusão de um tipo de conhecimento e de saber, que mais tem servido para cristalizar o pensamento jurídico dominante.

Palavras-chave: Direito; Campo Jurídico; Manuais; Pensamento jurídico dominante.
\end{abstract}

\begin{abstract}
The analyses on Law focus either on the formal elements, either on the instruments and, in this way, it reduces the possibility of understanding the Law itself. The notion of legal field used by Pierre Bourdieu becomes an important instrument to understand this social universe of the legal world, that organizes the relations and delimits spaces, where the "Law operators" concurs between themselves for the monopoly of the right to say the Law. In this direction, the notion of private property in manuals of "Property Law" or "Law of Things" allows to describe this struggle process that occurs inside the legal field, showing the construction of a practice and a proper legal speech, whose objectives are the production, reproduction and diffusion of a type of knowledge rather, than serve to crystallize the dominant legal thought.
\end{abstract}

Keywords: Law; Legal Field; Manuals; Dominant legal thought.

\begin{abstract}
O campo jurídico é o lugar de concorrência pelo monopólio do direito de dizer o direito (...). É com esta condição que se podem dar as razões quer da autonomia relativa do direito, quer do efeito propriamente simbólico de desconhecimento, que resulta da ilusão da sua autonomia absoluta em relação às pressões externas. (sem grifo no original) (BOURDIEU, 1989, p. 212)
\end{abstract}

\footnotetext{
*Professor do Programa de Pós-Graduação em Direito Ambiental da Universidade do Estado do Amazonas (PPDA-UEA). Pesquisador do Grupo de Pesquisa "Direito, Comunidades Tradicionais e Movimentos Sociais". Pesquisador do Projeto Nova Cartografia Social da Amazônia (PNCSA-UFAM-F.Ford).
} 


\section{Introdução: problema e objetivo}

A proposta de refletir o Direito a partir da noção de campo jurídico traduz uma tentativa de apreender o universo social específico no qual ele se produz, reproduz e difunde, sem a preocupação de tentar situar essa discussão no debate científico prevalente, que, ao focalizar na análise ora os elementos formais, ora os instrumentais (BOURDIEU, 1989, p. 209), tende a reduzir a possibilidade de compreensão do próprio Direito.

Para Pierre Bourdieu, o rompimento com esses esquemas de interpretação, que na maioria das vezes têm se colocado como antagônicos, possibilita promover "novas leituras" do Direito, no sentido de compreendê-lo no contexto das relações sociais que compõem a sociedade. Em outras palavras, as práticas e os discursos jurídicos devem ser tomadas como produto deste campo, determinado por relações de forças sociais que o estruturam e por uma lógica que delimita os espaços possíveis do Direito (BOURDIEU, 1989, p. 212-225), onde os "operadores do direito" concorrem pelo monopólio do direito de dizer o Direito (BOURDIEU, 1989, p. 212).

Ao considerarmos a existência de uma disputa que se estabelece no interior do campo jurídico, afastamos deliberadamente da idéia da "neutralidade" e da "universalidade" dos diferentes instrumentos de análise de uma ciência jurídica, em que estariam inscritos esquemas legítimos de interpretação e aplicação do Direito. Para além desse processo tem-se observado nas disputas mais recentes uma reivindicação de "homogeneidade jurídica universal", comprometida com um "projeto global de sociedade"

Neste sentido, a noção de propriedade privada contida nos manuais de "Direitos Reais" ou de "Direitos das Coisas" tomados preferencialmente neste trabalho permite explicitar esse processo de lutas que ocorre no interior do campo jurídico, evidenciando a construção de uma prática e de um discurso jurídico próprio, cujos objetivos são a produção, reprodução e difusão de um tipo de conhecimento e de saber que mais tem servido para cristalizar o pensamento jurídico dominante.

Portanto, o objetivo deste artigo consiste em analisar, a partir da noção de propriedade privada construída nos manuais, as práticas e discursos no contexto do campo jurídico, que tem imposto indistintamente enquanto uma "verdade jurídica". Trata-se de tentar compreender a forma como é construído o Direito, sendo que para isso vamos tomar a noção de propriedade privada apresentada e construída de

\footnotetext{
${ }^{1}$ Para Bourdieu há um intenso movimento que tem a pretensão de criar uma "homogeneização jurídica", a fim de atender aos propósitos de determinados grupos econômicos dominantes que atuam em toda parte. BOURDIEU, Pierre. Contrafogos 2: para um movimento social europeu. Trad. André Telles. Rio de Janeiro: Jorge Zahar, 2001. p.107.
} 
forma indistinta nos manuais de Direito. No caso deste artigo vamos tomar prevalentemente o manual de Direitos Reais de Orlando Gomes, pois esse manual se destaca dos demais.

\section{A constituição do campo jurídico}

O campo jurídico se constitui historicamente e funciona consoante sua lógica interna de relações ${ }^{2}$, inclusive com poderes para legitimar, autorizar e consagrar determinados "operadores do direito", conforme a noção operacional de campo jurídico de Bourdieu (1989, p. 209-254).

Para esse autor, a noção de campo jurídico concerne a um espaço social específico, autônomo ${ }^{3}$, no qual os "operadores" concorrem entre si pelo monopólio do direito de dizer o Direito. A capacidade reconhecida de interpretar e aplicar os instrumentos normativos, que impõem uma visão legítima do mundo social, permite que se possa dar razões à autonomia relativa deste campo (BOURDIEU, 1989, p. 12) organizado como um sistema de interações consoante com a pluralidade de instâncias de funções específicas, sistemas e "operadores do direito", que são definidos por sua posição, função e autoridade reconhecida nesta estrutura (BOURDIEU, 1968, p. 126).

É nesse espaço que se produz o discurso jurídico verdadeiro, em que se constroem os mecanismos e as instâncias que permitem separar os discursos verdadeiros dos falsos; o Estatuto daquele que é o responsável e o encargo de dizer a "verdade jurídica".

As partes constitutivas desse campo jurídico possuem interdependência funcional, no entanto são separadas por diferenças de peso funcional, definindo a posição hierárquica de cada um no campo, o que contribui para estruturá-lo de forma particular (BOURDIEU, 1968, p. 126), conforme uma lógica (BOURDIEU, 1968, p. 106) em que o discurso do juiz difere do promotor, que difere do procurador, que também difere do advogado.

A posição-hierarquia no campo será sempre mediatizada pela estrutura do campo jurídico (BOURDIEU, 1968, p. 111) ou, mais exatamente, por sua posição

${ }^{2}$ Tem-se evidenciado o papel cada vez mais relevante de formas de controle dos meios de acesso ao campo jurídico, como é caso da Ordem dos Advogados do Brasil, que o faz por meio do chamado "exame de ordem". Estes exames têm servido para "controlar" o ingresso de profissionais no campo jurídico.

${ }^{3}$ Segundo Bourdieu, em "uma carta dirigida a Conrad Schmidt, Engels observa o aparecimento do direito enquanto tal, ou seja, como 'esfera autônoma', acompanhada os progressos da divisão do trabalho que levam à constituição de um corpo de juristas profissionais" (BOURDIEU, Pierre. A economia das trocas simbólicas. Trad. Sergio Miceli. 5.ed. São Paulo: Perspectiva, 1999. p.101). 
em relação aos demais "operadores do direito" - e o capital simbólico acumulado tem peso determinante no posicionamento. Sabe-se que essa posição é também política, orientada segundo a relação com outras forças sociais, sobretudo pelo fato de que o Direito é importante instrumento para o processo de manutenção de determinada ordem social e econômica - isto é, há uma pluralidade de forças sociais que, em razão de seu poder econômico e político, está apta a impor suas decisões (BOURDIEU, 1968, p. 127).

Nesse sentido não há tomada de posição que seja passível de neutralidade, tal como sucede na representação ingenuamente idealizada do Direito. Portanto, o interesse em manter as condições sociais e econômicas de existência depende da possibilidade de se promover esta intenção que resulta do poder em legitimar, autorizar e consagrar práticas e discursos jurídicos. Para se compreender o processo de legitimação e consagração do Direito é necessário apreender as relações que se estabelecem fora deste campo, mas que também se encontram submetidas a distintos domínios de poder. O Direito também depende de outras instâncias que o determinam e condicionam, sendo que suas transformações se relacionam aos conflitos entre os diversos agentes.

A noção de campo jurídico, portanto, deve ser entendida como uma construção analítica, que serve para designar uma situação específica de relações sociais em que se mantém um espaço de disputas do direito para se dizer o Direito, porquanto somente em função de um mercado de serviços e bens (BOURDIEU, 1968, p. 110) é possível a formação desse corpo de profissionais do Direito - isto é, o estabelecimento de um verdadeiro campo jurídico como sistema de relações que se estabelecem entre os "operadores do direito". Para tanto essa noção de campo jurídico vai ser operada a partir da análise do discurso do direito de propriedade privada.

\section{Os manuais como um tipo de conhecimento do Direito}

No campo jurídico, o acesso à edição de livros jurídicos é importante prática utilizada pelos diferentes "operadores do direito" para efeito de legitimação e consagração no campo. A seu tempo, as editoras tornam-se fonte de autoridade (BOURDIEU, 1968, p. 108) para atendimento do mercado de serviços e bens jurídicos.

Para Bourdieu, as editoras seriam instâncias específicas de difusão cultural e, sobretudo, de seleção e consagração dos autores e de suas obras (BOURDIEU, 1968, p. 107). A utilização desses expedientes, segundo Carbonnier, serviria para marcar o caminho da autoridade pública, isto é, do reconhecimento público do intérprete (CARBONNIER, 1983, p. 157). 
No caso do campo editorial do Direito podemos falar que há no Brasil um monopólio exercido por algumas editoras que se encarregam de editar e distribuir a maioria das obras jurídicas, utilizadas diferentemente pelos "operadores do direito". Observamos que a disputa entre as editoras não se restringe ao mercado de consumo de livros jurídicos, no qual possuem um peso significativo, mas à forma de dizer o Direito.

Os autores que se colocam em posição de pensamento confrontante com a proposta editorial dessas editoras podem ser aceitos, tendo acesso aos meios editoriais, inclusive com obras publicadas, desde que já tenham sido consagrados no campo jurídico, envolvendo o reconhecimento em instâncias que se encontram legitimadas no campo, isto é, o que produzem deriva igual consagração. O que importa, sobretudo, é o fato de que esses campos de produção do pensamento jurídico, apesar de se colocar em oposição, coexistem no campo jurídico. Isto representa a capacidade desses autores de dizer a "coisa dita" sem sacrificar o assunto sujeito à proposição do debate, numa tentativa de estabelecimento de diálogo no campo jurídico. A consagração implica o reconhecimento da capacidade de se nomear, classificar e criar as coisas (BOURDIEU, 1989, p. 236-240). O poder de nomeação (BOURDIEU, 1989, p. 237), sobretudo em construir "verdades jurídicas" que, diferentemente das demais ciências, têm o poder de transformar, produz resultados imediatos.

O Direito, então, contribui para a produção e reprodução de uma dada ordem social, proclamando e definindo aquela ordem que será tida como exemplar. Ao consagrar determinada realidade, o Direito desconhece ou ignora as que possam coexistir. Portanto, a divisão da realidade leva à desconsideração ou à negação das demais visões, sendo daí que decorrem a força e a violência simbólica do Direito, que, além de construir (conceituando, classificando, organizando) uma dada realidade social, impõe uma definição que passa a ser legítima.

Por outro lado, a maioria das obras jurídicas não se ocupa com esse tipo de problema; as obras centram seus debates na construção ou aperfeiçoamento de instrumentos que possam resolver os conflitos sociais. Tal atitude "desconhece" a força do Direito em organizar o mundo social, determinando uma visão romântica de seu papel.

Nesse contexto de definição de uma realidade social, os manuais de direito, por serem instrumentos especializados, se apresentam como importantes repertórios utilizados de forma indiscriminada para a promoção e concretização dessas práticas, sobretudo pelo fato de que o monopólio na edição de livros jurídicos se restringe a algumas editoras. Como instrumento utilizado em todos os cursos jurídicos, sem exceção, os manuais impõem e asseguram uma forma-fórmula que permite a 
produção e reprodução de um tipo de conhecimento jurídico coadunado com uma definição da realidade que é considerada legítima.

Como o próprio termo sugere, os manuais são trabalhos elementares de Direito, escritos e oferecidos para estudantes e demais profissionais e que têm como objetivo facilitar o aprendizado (GOMES, 1958, p. 5-6; GOMES, 2004, p. IX-X). Contudo, o caráter que lhes é atribuído e o fato de ser utilizados como ferramentas de ensino nos cursos jurídicos não significam que eles sejam escritos por profissionais não capacitados ou desconhecidos. Ao contrário, são organizados e escritos por profissionais plenamente capacitados e reconhecidos nas suas respectivas disciplinas, cujo saber já foi consagrado pelo campo jurídico.

Esses autores colocam uma particularidade ao se apresentar como professores portadores das maiores titularidades acadêmicas, podendo ser colocados como teóricos da disciplina. A oposição entre o teórico e o prático que se estabelece na maioria dos sistemas não pode ser colocada de forma tão evidente no campo jurídico, sendo que a maioria esmagadora dos professores dos cursos jurídicos exerce outras atividades profissionais além do ensino. De fato há dificuldade de se ter essa separação, o que leva a afirmar que nem sempre os professores são os teóricos, diferentemente de outras tradições jurídicas. Ou melhor, o fato de não exercer atividade profissional pode representar um fator limitante para aquele profissional que pretende ministrar alguma disciplina de Direito.

A especificidade da disciplina jurídica enseja o domínio de um tipo de técnica ou tecnologia, bem como a estrutura de relações estabelecidas no campo jurídico; a importância hierárquica conferida a alguns profissionais permite o exercício concomitante das posições de teórico e prático. Conclui-se que o peso atribuído a cada uma das posições se relaciona às relações e à capacidade de impor a prevalência de um sobre o outro.

No entanto, devemos ressaltar a importância do papel das editoras que, estrategicamente, apresentam esses manuais numa posição de neutralidade e o fazem colocando-se na condição de professores, o que sugere uma posição de isenção a qualquer tipo de ideologia que possa comprometer o conteúdo dos manuais. Como se a síntese, que envolve procedimentos de organização e classificação do conteúdo do material da disciplina, pudesse ser realizada sem posição pessoal do autor, que se encontra eivado de tudo o que e como apreendeu.

Afinal, trata-se de manuais que seriam isentos per si, pois se preocupam com a síntese das disciplinas de determinada área do conhecimento jurídico. Estes autores se organizam e escrevem sobre o direito de família, sucessões, propriedade, contrato, não ficando restritos a uma disciplina de sua área. Observa-se, assim, o conhecimento jurídico acumulado que reafirma a posição hierárquica superior ocu- 
pada por esses autores no campo jurídico em que se perfilam no trabalho de sínteses teóricas que são tidas como mais prestigiosas (BOURDIEU, 1999, p. 165). Trata-se de assumir uma posição do "intelectual total" (BOURDIEU, 1999, p. 165), que se encontra capacitado para dizer sobre todas as coisas, independentemente de que elas possam corroborar no processo de aprendizado.

O quadro a seguir apresenta "Os Manuais de Direito das Coisas ou Direitos Reais Utilizados nos Cursos Jurídicos" mais comumente utilizados nos cursos jurídicos das faculdades de Direito de todo o Brasil. Tem-se um recorte proposital - em consideração à extensão do repertório dos manuais que se esparrama em todas as áreas que compreendem o estudo do Direito - que envolveu o mapeamento de uma disciplina do Direito: "direito das coisas" ou "direito reais".

Quadro 1: Os manuais de direiro das coisas ou direito reais utilizados nos cursos jurídicos

\begin{tabular}{|c|c|c|c|c|c|c|c|}
\hline \multirow{3}{*}{$\begin{array}{c}\text { № DE } \\
\text { ORDEM }\end{array}$} & \multirow{3}{*}{ AUTOR } & \multirow{3}{*}{ CURSO } & \multicolumn{5}{|c|}{ EDIÇÃO } \\
\hline & & & & & & & Edição \\
\hline & & & Local & Editora & Edição & Editora & $2002 / 2003$ \\
\hline \multirow{2}{*}{1} & \multirow{2}{*}{ Arnaldo Wald } & $\begin{array}{c}\text { Direito Civil } \\
\text { Brasileiro }\end{array}$ & \multirow{2}{*}{$\begin{array}{l}\text { Rio de } \\
\text { Janeiro }\end{array}$} & \multirow{2}{*}{$\begin{array}{l}\text { Lux } \\
\text { Ltda. }\end{array}$} & \multirow{2}{*}{1962} & \multirow{2}{*}{ Saraiva } & \multirow{2}{*}{$11^{\mathrm{a}}-2002$} \\
\hline & & $\begin{array}{l}\text { Direito das } \\
\text { Coisas }\end{array}$ & & & & & \\
\hline \multirow{3}{*}{2} & \multirow{3}{*}{$\begin{array}{c}\text { Caio Mario da } \\
\text { Silva Pereira }\end{array}$} & $\begin{array}{c}\text { Instituições } \\
\text { de Direito } \\
\text { Civil }\end{array}$ & \multirow{3}{*}{$\begin{array}{l}\text { Rio de } \\
\text { Janeiro-São } \\
\text { Paulo }\end{array}$} & \multirow{3}{*}{ Forense } & \multirow{3}{*}{1970} & \multirow{3}{*}{ Forense } & $18^{\mathrm{a}}$ \\
\hline & & $\begin{array}{c}\text { Direitos } \\
\text { Reais }\end{array}$ & & & & & 2003 \\
\hline & & Vol. IV & & & & & \\
\hline \multirow{3}{*}{3} & \multirow{3}{*}{$\begin{array}{c}\text { Maria Helena } \\
\text { Diniz }\end{array}$} & $\begin{array}{c}\text { Curso de } \\
\text { Direito Civil } \\
\text { Brasileiro }\end{array}$ & \multirow{3}{*}{ São Paulo } & \multirow{3}{*}{ Saraiva } & \multirow{3}{*}{1981} & \multirow{3}{*}{ Saraiva } & $17^{\mathrm{a}}$ \\
\hline & & $\begin{array}{c}\text { Direito das } \\
\text { Coisas }\end{array}$ & & & & & 2002 \\
\hline & & Vol. 4 & & & & & \\
\hline \multirow{2}{*}{4} & \multirow{2}{*}{$\begin{array}{l}\text { Orlando } \\
\text { Gomes }\end{array}$} & Direitos & \multirow{2}{*}{$\begin{array}{l}\text { Rio de } \\
\text { Janeiro }\end{array}$} & \multirow{2}{*}{ Forense } & \multirow{2}{*}{1958} & \multirow{2}{*}{ Forense } & $19^{\mathrm{a}}$ \\
\hline & & Reais & & & & & 2003 \\
\hline \multirow{3}{*}{5} & \multirow{3}{*}{$\begin{array}{c}\text { Silvio } \\
\text { Rodrigues }\end{array}$} & Direito Civil & \multirow{3}{*}{ São Paulo } & \multirow{3}{*}{$\begin{array}{c}\text { Max } \\
\text { Limonad }\end{array}$} & \multirow{3}{*}{1964} & \multirow{3}{*}{ Saraiva } & $27^{\mathrm{a}}$ \\
\hline & & $\begin{array}{c}\text { Direito das } \\
\text { Coisas }\end{array}$ & & & & & 2002 \\
\hline & & Vol. 5 & & & & & \\
\hline \multirow{3}{*}{6} & Washington de & $\begin{array}{c}\text { Curso de } \\
\text { Direito Civil }\end{array}$ & & & & & $37^{\mathrm{a}}$ \\
\hline & $\begin{array}{l}\text { Barros } \\
\text { Monteiro }\end{array}$ & $\begin{array}{c}\text { Direito das } \\
\text { Coisas }\end{array}$ & São Paulo & Saraiva & (?) & Saraiva & 2003 \\
\hline & & Vol. 3 & & & & & \\
\hline
\end{tabular}


O fato de os manuais serem utilizados nas disciplinas de Direito, sem exceção, em todos os cursos jurídicos no Brasil, faz com sejam vistos como instrumento "natural" ao ensino jurídico. Tem-se a impressão de que é impossível ministrar e aprender sem esse tipo de expediente de ensino jurídico, o que determina e impõe uma forma do conhecimento jurídico, isto é, as obras consideradas legítimas para o ensino jurídico (BOURDIEU, 1999, p. 120). Para Bourdieu, o sistema de ensino tem um papel fundamental no processo de legitimação cultural ao converter determinadas obras em legítimas, estabelecendo e determinando o que e como deve ser transmitido (BOURDIEU, 1999, p. 120).

Ao ser tomados os manuais como naturais, não se coloca em causa sua estrutura, coerência e conteúdo, às vezes incompatível com a atualidade do debate dogmático. Nesse sentido, o próprio sistema de ensino contribui para manter a defasagem cultural, ocorrendo o que Bourdieu (1999, p. 123) denomina "inculcação". Trata-se de controlar consciente e inconscientemente a prática dos modelos explicativos (BOURDIEU, 1999, p. 125).

Os manuais representam, assim, o conteúdo-síntese de cada disciplina, com uma linguagem que mescla a erudição e coloquialidade, acusando uma forma de linguagem que se ocupa em apresentar esse conteúdo como se fosse neutro e universal. Trata-se da própria forma de linguagem jurídica (BOURDIEU, 1989, p. 215-216). Neles não há opinião definida de autor acerca dos temas tratados, que se mostram distantes da realidade do leitor.

Ocupam-se em historiar as categorias e teorias para daí classificá-las e reclassificá-las com o propósito de dar sentido à disciplina, o que torna a leitura enfadonha e cansativa. Tal procedimento é acompanhado de transcrições ou citações do Código e das leis concernentes.

A preocupação pedagógica dos autores em historiar as categorias e teorias, numa tentativa de contextualizar a sua produção, é um dado importante e que deve ser considerado no processo de análise. $\mathrm{O}$ fato de ser incorporadas de forma fragmentada ao texto do manual, bem como a posição acrítica dos autores ${ }^{4}$ descurada de qualquer tipo de análise em relação aos autores tomados e referenciados, tem

\footnotetext{
${ }^{4}$ Gomes, ao tratar da "síntese da evolução história" da propriedade, no manual de Direitos Reais das edições de 1958 e 1990, afirma que no regime em que vivenciamos "o direito de propriedade é elevado à condição de direito natural, em pé de igualdade com as liberdades fundamentais". Todavia, a última edição do mesmo manual já tem a preocupação de trazer à obra a colação de um estudo crítico, que pode ser sintetizado com a citação do parágrafo final "Autonomia da vontade, liberdade individual e propriedade privada, transmigraram dos fundamentos teóricos e ideológicos do Estado liberal para os princípios de direito, com a pretensão de universalidade e intemporalidade". (GOMES, O., Direitos reais, 19.ed, op. cit., p.116). (sem grifo no original).
} 
dificultado o processo de aprendizado do Direito, ${ }^{5}$ pois nesse processo os estudantes são tratados como meros receptadores, ausentes de qualquer tipo de raciocínio especulativo e problemático do Direito.

É preciso colocar em causa o tipo de produção que se apresenta como síntese acabada de determinada disciplina, agrupando idéias e autores que são aceitos sem qualquer exame (FOUCAULT, 1997, p. 23-34). Daí a necessidade de promover um primeiro trabalho que possa apontar o problema da continuidade desse tipo de expediente, que tem uma função precisa no sistema jurídico, qual seja: visão, produção e reprodução de uma forma de conhecimento do Direito num certo sentido, contribuindo para que se mantenha a defasagem da cultura jurídica produzida pelo campo jurídico.

Essa espécie de imobilidade do ensino jurídico está relacionada com a função do próprio Direito, que diz respeito à autonomia do sistema e à segurança jurídica, e essa própria imobilidade tem sido paradoxalmente o motivo da insegurança (LOPES, 1981, p. 369-371). Não nos colocamos sob a hipótese de refutar definitivamente tais práticas, mas tentamos alertar para o fato de que esses manuais não são práticas naturais de ensino jurídico, e sim de construções cujas regras devem ser conhecidas e as justificativas, controladas por todos os "operadores do direito" (FOUCAULT, 1997, p. 29).

A noção em questão é tomada como instrumento operacional, cuja ocupação se restringe tão-somente a trazer para a reflexão determinadas práticas de ensino que são comumente utilizadas nos cursos jurídicos, nos quais o aprendizado crítico e reflexivo é acionado dependendo daqueles que promovem o ensino. Trata-se, pois, de enfocar os manuais como se fossem problemas, reconhecendo que não representam tranqüilidade para o ensino-aprendizagem do Direito.

Observa-se a longevidade das edições dos manuais constantes do quadro, que datam da década de 1960, coincidindo com a reforma educacional ocorrida no Brasil. Na época defendia-se a importância de a universidade ter um caráter eminentemente pragmático e utilitarista para a formação de quadros técnicos e gerenciais, em função do modelo de desenvolvimento que se propunha (FARIA; CAMPILONGO, 1991, p. 9-11). Os quadros técnicos iriam compor a burocracia que faltava para o desenvolvimento do país, garantindo a passagem de um sistema patriarcal para um sistema moderno operado pelo Estado militar.

\footnotetext{
${ }^{5}$ A exemplo da dificuldade que se tem em poder afirmar que para as situações de "Direito das Coisas" ou "Direitos Reais" há prevalência do direito real sobre o direito pessoal. A despeito do tratamento dado em relação a esse tema, atribuindo significado e distinções, direito real e direito pessoal. A contraposição entre direito real ou direito pessoal, aparentemente técnica, encerra uma ordem de opções ideológicas e culturais que não são expressas e que permanecem veladas nos manuais de direito.
} 
Assim, desde o final da década de 1960 a maioria das edições dos manuais de "Direito Privado" vem sendo produzida, reproduzida e difundida, o que permite a constatação de que estamos formando um tipo de profissional do Direito produto de uma prática de ensino que tem as editoras como participantes ativas no processo. Ao se referir à leitura dos manuais de "Direito das Coisas" e "Direitos Reais", de Caio Mario da Silva Pereira, Orlando Gomes, Maria Helena Diniz, Washington de Barros Monteiro, Silvio Rodrigues e Arnold Wald, Tepedino chama atenção para o dogmatismo que impera, impedindo qualquer tipo de transformação, inclusive aquelas ditadas pelos dispositivos legais:

Todavia, os civilistas não se deram conta de tais modificações em toda a sua amplitude, mantendo-se condicionados à disciplina da propriedade pré-vigente. Uma confirmação dessa constatação obtém-se do exame dos manuais, cujas novas edições, após 1988, não trouxeram alterações substanciais. Os autores limitaram-se a incluir nos antigos textos mudanças pontuais ou supressões de simples preceitos não recebidos pela Constituição (TEPEDINO, 2001, p. 268). (sem grifo no original).

Segundo Tepedino, esses manuais editam ainda hoje a propriedade privada circunscrita ao conteúdo do Código Civil de 1916. Observa-se que, na primeira edição do manual de "Direitos Reais", Orlando Gomes informava o problema e a necessidade de "atualização" do conteúdo do manual recém-publicado:

Concisa atualização de conhecimentos, através de breve análise das transformações gerais por que passam a propriedade e outros direitos reais, deverá ser feita, quanto antes, em vernáculo. $\mathrm{O}$ velho arcabouço do domínio e dos direitos sobre a coisa alheia, ainda persistente, é, assim, focalizado de um ângulo em que sua renovação ganha relevo nos traços marcantes. (GOMES, 1958, p. 5-6) ${ }^{6}$. (sem grifo no original).

Observa-se que, ao longo dos anos, a "revisão", a "atualização" e o "aumento", para a maioria dos manuais, vêm se restringido à mera compilação dos dispositivos legais, sem qualquer tipo de compromisso com a alteração do conteúdo, mesmo que esses dispositivos os obriguem. Quando a revisão, a atualização e o aumento da obra se resumem aos procedimentos de compilação e incorporação dos novos dispositivos legais, a forma de compreender o Direito como doutrina somente tem valor se estiver ancorada nos códigos e leis.

\footnotetext{
${ }^{6}$ Em 1952, Gomes já expressa opinião a respeito do tema. Conferir GOMES, Orlando. Significado da evolução contemporânea do direito de propriedade. Revista dos Tribunais, São Paulo, ano 41, v. 205, p. 3-15, nov. 1952.
} 
Assim, paradoxalmente, atribuem valor secundário à doutrina que é produzida. ${ }^{7}$ A maioria ${ }^{8}$ dos manuais se apresenta com uma roupagem nova, mas com conteúdo ultrapassado, datado e periodizado na época que foi editada, período e contexto histórico. Nesse sentido, esses manuais corroboram a visão, produção e reprodução de um tipo de conhecimento dogmático do Direito, que se coloca como verdadeiro, sobretudo por "desautorizar" todos aqueles que não se utilizam desse expediente.

Ao impor a definição da leitura desse tipo de repertório dogmático, as editoras se posicionam como instâncias importantes no processo que distingue as obras a ser consideradas legítimas ou consagradas. Essas editoras têm se colocado alheias às transformações que se relacionam ao debate teórico da disciplina e, de certa forma, refutam o debate sobre o que tem sido denominado "constitucionalização" ou "repersonalização" do Direito Privado.

O debate jurídico sobre o direito de propriedade pode ser ilustrativo desses fatos e é possível observar a posição das editoras de livros jurídicos, que se colocam em campos antagônicos ao do Direito. A verificação desses argumentos será pela análise dos manuais de "direito das coisas" ou "direitos reais" que são editados e distribuídos por essas editoras que detêm o monopólio em face de uma outra produção sobre o mesmo tema (denominada como autônoma por não estar inscrita nos manuais, encontrando-se circunscrita em um debate crítico sobre o Direito na sociedade contemporânea).

\section{0 discurso da propriedade: posições no campo jurídico}

A força dos discursos jurídicos e de sua difusão se relaciona ao capital simbólico que determina a posição hierárquica ocupada pelo "operador do direito" no campo jurídico, sendo que, a depender da posição do "operador", mais próxima ou distante do campo do poder, o discurso se apresenta com roupagem característica.

A própria estrutura do Direito, apresentando conceitos, categorias e normas vagas e gerais, corrobora essa prática, fazendo com que seja possível que os discur-

\footnotetext{
${ }^{7}$ Em Cruet podemos conferir o papel secundário atribuído à doutrina do Direito. Segundo o autor, a despeito das doutrinas se colocarem como se fossem absolutas, são passageiras e relativas (CRUET, Jean. A vida do direito e a inutilidade das leis. 2. ed. Leme: EDIJUR, 2003).

${ }^{8}$ Tem-se como exceção o manual de Direitos Reais de Orlando Gomes (2004), que sofreu mudanças significativas quando da atualização de seu conteúdo, a exemplo da posição adotada pelo atualizador em defender a proposta de Fábio Konder Comparato quanto à ausência de direito de reintegração de posse dos imóveis que descumprem a função social (GOMES, O. Direitos reais, 19. ed., op. cit., p.110).
} 
sos jurídicos se apresentem com certa "elasticidade", de forma complementar ou mesmo antagônica. Todavia, ressaltamos o fato desses discursos jurídicos serem aceitos, desde que sua representação esteja de acordo com a normalidade em face de todas as práticas (BOURDIEU, 1989, p. 213-214). A definição de "normalidade", portanto, também se encontra no campo jurídico de disputas, onde os intérpretes autorizados "inventam" o Direito.

O duplo sentido que pode ser atribuído aos conceitos, às categorias ou às normas permite a possibilidade de construir os discursos jurídicos sob diversas formas e conteúdos. Contudo, a capacidade de operar as transformações tem a ver com relações de força que se estabelecem no interior do campo jurídico. É por isso que acreditamos na capacidade do Direito servir como instrumento para transformar a realidade.

Ao delimitar esse espaço, o discurso jurídico tem o poder de construção e desconstrução da realidade ao declarar, constituir ou extinguir, o que o diferencia das demais ciências; assim é que se consolida, pois consagra a representação oficial do mundo social, que tende a se colocar sobre todos, ou pessoas ou grupos (BOURDIEU, 1989, p. 236-240).

É assim que se elabora o discurso sobre o direito de propriedade privada. Observa-se que esse discurso se posiciona de forma antagônica, representando sobretudo posturas diferenciadas em relação à compreensão do Direito, a saber: os que defendem um tipo de propriedade privada absoluta, livre e desembaraçada de qualquer tipo de ônus, e os que procuram relativizar a idéia, funcionalizando a propriedade privada aos interesses sociais. Por isso procura analisar esses discursos tomando como referência os manuais de "direito das coisas" ou "direito real" em uma outra produção à qual denominamos autônoma e que se encontra inscrita na formulação de um debate crítico sobre o Direito Privado.

Apresentamos a oposição entre esses diferentes repertórios de forma proposital para evidenciar as diferenças dos discursos jurídicos, a despeito de que se encontrem assentados num mesmo ordenamento jurídico. Afinal, qual seria a razão de o mesmo direito ensejar discursos diversos? Ou melhor, qual seria a razão de o mesmo direito, embasado nas mesmas leituras teóricas, ${ }^{9}$ ensejar discursos tão diversos?

No caso, estamos nos reportando às edições de 2004, 1990 e 1958 do manual de Direitos Reais, de Gomes, e aos estudos de Tepedino (2001; 1989), sobretudo. O recorte arbitrário que se faz tem como preocupação única trazer para o debate

\footnotetext{
${ }^{9}$ Pode-se constatar que as leituras teóricas utilizadas por Gomes e Tepedino para debater o direito de propriedade são praticamente as mesmas: P. Perlingieri, S. Pugliatti, P. Rescigno e S. Rodotá.
} 
autores com os quais há uma identificação. Trata-se de importantes profissionais do Direito, que a seu tempo contribuíram ou contribuem com a produção do conhecimento jurídico.

A necessidade de nos reportarmos às três edições dos Direitos Reais se deve ao fato de que no período compreendido entre a primeira edição (1958) e a última (2004) foram editados novos textos legais (a Constituição Federal de 1988 e o Código Civil de 2002), transformando substancialmente o conteúdo do direito de propriedade, o que implicou ou não a formulação e elaboração de novos discursos. Assim, cada uma das edições se relaciona a um novo texto legal: a edição de 1958 remete ao Código Civil de 1916; a de 1990, à CF de 1988; e a de 2004 ao CC de 2002.

A "constitucionalização" e a "teoria crítica do direito civil contemporâneo" nasceram e se desenvolveram nesta travessia, representando "um elo dialético entre o presente e o futuro alicerçado no legado construtivo do pretérito" (FACHIN, 1004, p. 2), representando a riqueza da construção doutrinária no período, que se coloca em face dos discursos dos manuais.

Como visto, as inovações legislativas, que ensejaram debates e formulação teórica, pouco ou quase nada contribuíram no processo de "revisão" e "atualização" dos manuais. ${ }^{10}$ As diferenças de posições teóricas permitem constatar as disputas pelo direito de dizer o "Direito" no campo jurídico - mais do que isto, de dizer o "Direito oficial".

Observa-se que os autores desses manuais de Direitos Reais e Direitos das Coisas se colocaram distantes da edição desses novos textos, sobretudo em relação à Constituição Federal de 1988, mantendo os discursos sobre a propriedade tal qual o Código Civil de 1916, sendo que somente com a edição do novo Código Civil de 2002, que incorporou as transformações desse direito (a exemplo da "função social da propriedade"), é que se ocuparam em atualizar o direito de propriedade. Em outras palavras, a despeito de nos referirmos à edição de 1990, todas as edições posteriores do manual de Direitos Reais de Orlando Gomes, à exceção da edição de 2004, mantiveram-se como a primeira edição, que data de 1958.

O procedimento adotado (frise-se: não se tem qualquer tipo de pretensão de analisar a obra do autor) consiste em dispor lado a lado essas edições do manual de Direitos Reais de Orlando Gomes - a edição de 1958 (CC de 1916), a de 1990 (CF

\footnotetext{
${ }^{10} \mathrm{~A}$ indiferença dos autores em relação às transformações, inclusive doutrinárias, não implica que não estivessem acompanhando os debates a respeito dos temas. Ver, na edição de 1990, as referências bibliográficas utilizadas por Gomes (Direitos reais, 10. ed., op. cit., p. 1). Ao contrário, observamos que esses autores se encontravam atualizados em relação ao que era produzido em outros lugares do mundo, a despeito das dificuldades da época.
} 
de 1998) e a de 2004 (CC de 2002) -, a fim de que se possa constatar os argumentos do pesquisador, chamando atenção para o fato de que esse aspecto já havia sido destacado por Tepedino (2001, p. 268). Como auxílio a este procedimento de pesquisa toma-se emprestadas as reflexões e formulações sobre a "constitucionalização" e "teoria crítica do direito civil contemporâneo".

As edições do manual de Direitos Reais de 1958 e 1990, de Gomes, apresentaram atualizações pouco significativas, mantendo toda a estrutura da obra ${ }^{11}$ - inclusive o que seriam os critérios para sua definição: "unitário", "absoluto", "perpétuo" - e limitando-se a retirar o capítulo "Transformações Gerais da Propriedade" da edição de 1958 (GOMES, 1958, p.126-151) e a incluir o tópico "Função Social da Propriedade" na edição de 1990 (GOMES, 1990, p. 92-106). Ou melhor, manteve a formulação do direito de propriedade tal qual o CC de 1916, de que seria um:

direito complexo, embora unitário (se bem que unitário). Apresenta-se, em verdade, (consistindo num) como um feixe de direitos, que se resumem (consubstanciado) nas faculdades de usar, gozar, dispor e reivindicar a coisa sobre a qual incide (que lhe serve de objeto). (GOMES, 1958, p. 118-119; GOMES, 1990$, p. 85$)^{12}$

A leitura das transformações que o texto constitucional de 1988 promoveu em relação ao direito de propriedade foram diferenciadas (TEPEDINO, 2001; TEPEDINO, 1989, p. 73-78). Então, tem-se uma tentativa de situar o debate sobre a "função social da propriedade" no manual de Direitos Reais, de Orlando Gomes, edição de 1990.

A noção de "função social da propriedade" permitiu que o direito de propriedade fosse encarado pela doutrina como uma "complexa situação jurídica subjetiva, ativa e passiva", que ensejaria "direitos", "obrigações” e "ônus” (GOMES, 1990, p.

\footnotetext{
${ }^{11}$ Contudo, questões mais pontuais também foram observadas: o texto é praticamente o mesmo (ver tópicos sobre "Conceito" e "Conteúdo", por exemplo), com melhorias podendo ser atribuídas ao formato da edição; à atualização em relação aos interlocutores do autor na edição de 1958, como Marx e os problemas afetos a esse debate já na edição de 1990, com os juristas italianos, sobretudo; à inclusão de um parágrafo no tópico "Conteúdo" afirmando que "O direito de propriedade é assegurado na Constituição, salvo o caso de desapropriação, até por interesse social” na edição de 1990 (p. 86); e à inclusão de um tópico "Propriedade Urbana e Rural" em que não há sequer referência ao texto constitucional de 1988 (artigos 182 e ss. que se referem à "Política Urbana", e 183 e ss., à "Política Agrícola e Fundiária e da Reforma Agrária”).

${ }^{12}$ As partes entre parênteses se referem à redação da edição de 1990. Como visto, esta definição do que seria o direito de propriedade não se distancia daquela formulada pelo conselheiro Lafayette Rodrigues Pereira: "O Direito de propriedade, em sentido genérico, abrange todos os direitos que formão o nosso patrimônio, isto é, todos os direitos que podem ser reduzidos á valor pecuniário" (PEREIRA, Lafayette Rodrigues. Direito das cousas. Rio de Janeiro: Garnier, 1877. v. 1. p. 73).
} 
96). ${ }^{13}$ Contudo, essa qualificação não seria suficiente para a definição do princípio da "função social da propriedade", pois enquanto o termo função "não toca no conteúdo do direito" (GOMES, 1990, p. 97), o social é ambíguo (GOMES, 1990, p. 97). Para ele, "sua solução exige a determinação do alvo do conceito" (GOMES, 1990, p. 99). Haveria, portanto, uma dificuldade em converter essa noção de "função social" num conceito jurídico, dada sua elasticidade.

A seu tempo informa outros problemas, como o fato de que a função social da propriedade não teria valor normativo porque não se consubstancia nas normas restritivas do moderno direito de propriedade (GOMES, 1990, p. 99-100).

A hipótese assumida coloca-o em consonância com o que se denomina "dogmática tradicional", ao considerar que a propriedade privada deva ser regulamentada exclusivamente pelo Código Civil (TEPEDINO, 1989, p. 77; TEPEDINO, 2001, p. 275). A Constituição é entendida como uma carta contendo "princípios" e "valores", que por sua própria natureza não pode ser traduzida em regras ou se constituir de normas que impõem ou orientam determinadas condutas.

No caso, as regras ou normas constitucionais somente poderiam ser operadas de forma excepcional ou residual, sendo que de forma alguma a atividade interpretativa poderia incidir sobre elas. Esta noção operacional do Direito insiste em afirmar a separação entre os dispositivos e a Constituição. A "função social" tem sido concebida como algo estranho ao Código Civil e de difícil operacionalização (TEPEDINO, 2001, p. 269), sobretudo por se tratar de uma noção sem conteúdo definido e que se encontra no texto constitucional.

Esses mesmos argumentos apresentados como problemas são utilizados justamente como soluções para outro conjunto de intérpretes, que justifica a eficácia e aplicação imediata desta noção atribuindo novo conteúdo ao direito de propriedade: "A propriedade, todavia, na forma como foi concebida pelo Código Civil, simplesmente desapareceu no sistema constitucional brasileiro, a partir de 1988" (TEPEDINO, 2001, p. 283).

Ocorre que a formulação desse discurso acontece "fora" da disciplina. "Fora" porque é elaborado numa perspectiva crítica e inovadora, que se posiciona em face da dogmática tradicional. No caso, ancora a propriedade privada da terra às situações de fato que são interpretadas em consonância com os princípios do texto constitucional.

O primeiro obstáculo ultrapassado é o de que a propriedade privada não se trata de algo natural, sendo produto das relações sociais, econômicas e culturais

\footnotetext{
${ }^{13}$ Para Gomes, o uso corrente da noção de "função social da propriedade" nas Constituições se deve a uma série de idéias que são movimentadas por seus propósitos, mas que nem sempre são colocados de forma clara (GOMES, O. Direitos reais, 10. ed., op. cit., p. 97).
} 
(COMPARATO, 1986, p. 71-79; FACHIN, 1987, p. 16-39). ${ }^{14}$ Perlingieri afirma que a propriedade não é uma coisa universal e imutável, mas uma noção extremamente variável no tempo e no espaço (PERLINGIERI, 1971, p. 4; p. 59). Aparentemente simples, esse procedimento tem uma importância significativa para a compreensão do Direito, pois torna possível a afirmação de que a propriedade privada pode assumir outros conteúdos e feições que não aqueles consagrados pelo Código Civil de $1916 .{ }^{15}$

No caso, a propriedade privada e a "função social da propriedade" passam a ser lidas no contexto do ordenamento jurídico, em referência ao tratamento dado pela Constituição Federal de $1988 .{ }^{16} \mathrm{O}$ fato de a propriedade e a função social terem sido tratadas, inclusive no capítulo que diz respeito aos "direitos e garantias fundamentais", não teria razão se não fosse para instrumentalizar toda Constituição (TEPEDINO, 1989, p. 75). Apesar do conteúdo "misterioso" e vago da "função social da propriedade", esse princípio deve ser orientado pelos princípios e objetivos fundamentais da República (arts. $2^{\circ}$ e $3^{\circ}$ ), que têm na dignidade da pessoa humana regra basilar (TEPEDINO, 1989, p. 75).

\section{Considerações finais}

A descrição das "práticas jurídicas" que assumem conteúdos diversos sobre o mesmo Direito, bem como a utilização de recursos que permitem colocá-las face a face, são procedimentos da pesquisa que contribuem para uma análise acurada sobre as "verdades jurídicas".

A noção de propriedade privada tomada dos manuais de Direito Reais ou Direito das Coisas representa produto dessas "práticas jurídicas" que se desenham no interior do campo jurídico. No caso ficou evidente que as interpretações em relação à noção de propriedade privada se apresentam como conflitantes, na medida em que representam os interesses e as posições dos diversos "operadores do direito".

Os discursos contidos nos manuais apresentam uma noção de propriedade privada. Vale lembrar que esses discursos são alimentados no interior do campo

\footnotetext{
${ }^{14}$ A listagem de autores "fora" da ciência jurídica que pesam a propriedade privada como produto das relações sociais, econômicas é extensa. Entre tantos, fazemos referência ao trabalho de Engels sobre a origem da família, da propriedade privada e do Estado (ENGELS, Friedrich. A origem da família, da propriedade privada e do estado. Trad. Leandro Konder. 16. ed. Rio de Janeiro: Bertrand Brasil, 2002). ${ }^{15}$ As observações de Orlando Gomes a respeito do Direito já haviam anunciado esse debate (GOMES, O. Significado..., op. cit.; GOMES, O. Raízes históricas e sociológicas do código civil brasileiro. Salvador: Universidade da Bahia, 1958).

${ }^{16}$ Ver incisos II e III do art. 170, e incisos XXII e XXIII, do art. 5.
} 
jurídico, no sentido de assegurar a sua legitimação. Admitindo-se que é nesse espaço que o Direito é construído, é possível reafirmar a noção de disputas no campo jurídico e problematizar a própria idéia de universalidade e neutralidade do Direito, que se colocam como "obstáculo" para a própria compreensão da propriedade privada e do próprio Direito.

\section{Referências}

BOURDIEU, Pierre. Campo intelectual e projeto criador. In: POUILLON, J. et al. Problemas do estruturalismo. Rio de Janeiro: Zahar, 1968. Brasil, 1989.

O poder simbólico. Trad. Fernando Tomaz. Rio de Janeiro: Bertrand

. A economia das trocas simbólicas. Trad. Sergio Miceli. 5. ed. São Paulo: Perspectiva, 1999.

. Contrafogos 2: para um movimento social europeu. Trad. André Telles. Rio de Janeiro: Zahar, 2001.

CARBONNIER, Jean. Flexible Droit: textes pour une sociologie du droit sans rigueur. Paris: LGDJ, 1983.

COMPARATO, Fábio Konder. Função social da propriedade dos bens de produção. Revista de Direito Mercantil, Industrial, Econômico e Financeiro, São Paulo, ano XXV, n. 63, p. 71-79, jul./set. 1986.

CRUET, Jean. A vida do direito e a inutilidade das leis. 2. ed. Leme: EDIJUR, 2003.

ENGELS, Friedrich. A origem da família, da propriedade privada e do estado. Trad. Leandro Konder. 16. ed. Rio de Janeiro: Bertrand Brasil, 2002. FACHIN, Luiz Edson. Da propriedade como conceito jurídico. Revista dos Tribunais, São Paulo, ano 76, v. 621, p. 16-39, jul. 1987.

. Introdução. Das raízes do direito civil brasileiro contemporâneo.

In: GOMES, Orlando. Direitos reais. Rev. atual. e aum. por Luiz Edson Fachin. 19. ed. Rio de Janeiro: Forense, 2004.

FARIA, José Eduardo; CAMPILONGO, Celso Fernandes. A sociologia jurídica no Brasil. Porto Alegre: Sergio Antonio Fabris, 1991.

FOUCAULT, Michel. A arqueologia do saber. Trad. Luiz Felipe Baeta Neves. 5. ed. Rio de Janeiro: Forense Universitária, 1997.

. A ordem do discurso. Trad. Laura Fraga de Almeida Sampaio. 6. ed. São Paulo: Loyola, 2000. 
GOMES, Orlando. Significado da evolução contemporânea do direito de propriedade. Revista dos Tribunais, São Paulo, ano 41, v. 205, p.3-15, nov. 1952.

. Raízes históricas e sociológicas do código civil brasileiro. Salvador: Universidade da Bahia, 1958.

. Direitos reais. Rio de Janeiro: Forense, 1958.

. Direitos reais. 10. ed. Rio de Janeiro: Forense, 1990.

. Direitos reais. Rev. atual. e aum. por Luiz Edson Fachin. 19. ed. Rio de Janeiro: Forense, 2004.

LOPES, José Reinaldo de Lima. Função social do ensino da ciência do direito.

Revista de Informação Legislativa, Brasília, ano 18, n. 72, p. 369-371, out./ dez. 1981.

SHIRAISHI NETO, Joaquim. O direito das minorias: passagem do "invisível" real para o "visível" formal. Curitiba: Programa de Pós-graduação em Direito da Universidade Federal do Paraná (PPGD/ UFPR), 2004 (Tese de Doutorado). TEPEDINO, Gustavo. A nova propriedade (o seu conteúdo mínimo entre o código civil, a legislação ordinária e a constituição). Revista Forense, Rio de Janeiro, ano 85, v. 306, p. 73-78, abr./maio/jun. 1989.

. Código civil, os chamados microssistemas e a Constituição: premissas para uma reforma legislativa. Revista da Faculdade de Direito da UERJ, Rio de Janeiro, n. 6 e 7, p. 20, 1998-1999.

. Temas de direito civil. 2. ed. Rio de Janeiro/São Paulo: Renovar, 2001.

PEREIRA, Lafayette Rodrigues. Direito das cousas. Rio de Janeiro: Garnier, 1877. v. 1.

PERLINGIERI, Pietro. Introduzione alla problematica della proprietá.

Camerino: Jovene, 1971. 